\title{
Early versus late Gamma Knife radiosurgery following transsphenoidal resection for nonfunctioning pituitary macroadenomas: a matched cohort study
}

\author{
I. Jonathan Pomeraniec, BS, Robert F. Dallapiazza, MD, PhD, Zhiyuan Xu, MD, \\ John A. Jane Jr., MD, and Jason P. Sheehan, MD, PhD \\ Department of Neurosurgery, University of Virginia Health System, Charlottesville, Virginia
}

OBJECTIVE Gamma Knife radiosurgery (GKRS) is frequently employed to treat residual or recurrent nonfunctioning pituitary macroadenomas. There is no consensus as to whether GKRS should be used early after surgery or if radiosurgery should be withheld until there is evidence of radiographic progression of tumor.

METHODS This is a retrospective review of patients with nonfunctioning pituitary macroadenomas who underwent transsphenoidal surgery followed by GKRS between 1996 and 2013 at the University of Virginia Health System. Patients were stratified based on the interval between resection and radiosurgery. Operative results and imaging and clinical outcomes were compared across groups following early ( $\leq 6$ months) or late (>6 months) radiosurgery.

RESULTS Sixty-four patients met the study criteria and were grouped based on early $(n=32)$ or late $(n=32)$ GKRS following transsphenoidal resection. There was a greater risk of tumor progression after GKRS in the late radiosurgical group ( $p=0.027$ ) over a median radiographic follow-up period of 68.5 months. Furthermore, there was a significantly higher occurrence of post-GKRS endocrinopathy in the late radiosurgical cohort $(p=0.041)$. Seventeen percent of patients without endocrinopathy in the early cohort developed new endocrinopathies during the follow-up period versus $64 \%$ in the late cohort $(p=0.036)$. This difference was primarily due to a significantly higher rate of tumor growth during the observation period of the late treatment cohort $(p=0.014)$. Of these patients with completely new endocrinopathies, radiation-associated pituitary insufficiency developed in 1 of 2 patients in the early group and in 3 of 7 (42.9\%) patients in the late group.

CONCLUSIONS Early treatment with GKRS appears to decrease the rate of radiographic and symptomatic progression of subtotally resected nonfunctioning pituitary macroadenomas compared with late GKRS treatment after a period of expectant management. Delaying radiosurgery may place the patient at increased risk for adenoma progression and endocrinopathy.

http://thejns.org/doi/abs/10.3171/2015.5.JNS15581

KEY WORDS Gamma Knife; radiosurgery; pituitary surgery; macroadenoma; nonfunctioning; transsphenoidal resection; stereotactic radiosurgery

$\mathrm{N}$ ONFUNCTIONING pituitary adenomas constitute approximately $15 \%$ to $30 \%$ of pituitary tumors ${ }^{10,16}$ and typically present with symptoms of mass effect, including vision loss, headaches, and hypopituitarism from compression of the normal pituitary gland. Selective adenomectomy via a transsphenoidal approach remains the primary treatment modality by providing decompression and the prospect for cure. Complete resection rates vary significantly and can be limited due to tumor size and propensity for microscopic invasion of the surrounding structures. ${ }^{2,5,31,32,43,56}$
Previously reported long-term outcomes following transsphenoidal surgery for nonfunctioning macroadenomas suggest that even gross-total resection carries a $10 \%$ to $20 \%$ rate of tumor recurrence at distant follow-up. $6,8,9$, $13,19,21,34,43,46,58,64,66$ Subtotal resection without adjuvant treatment reportedly results in the progression of adenoma growth in $50 \%$ to $60 \%$ of patients within 10 years of surgery. ${ }^{9,22,34,43,46,48}$ For these reasons, patients with nonfunctioning tumors may undergo secondary operations and/ or adjuvant radiotherapy for the treatment of residual or progressive disease. ${ }^{9}$

ABBREVIATIONS GKRS = Gamma Knife radiosurgery; IGF-1 = insulin-like growth factor-I.

SUBMITTED March 13, 2015. ACCEPTED May 7, 2015.

INCLUDE WHEN CITING Published online October 30, 2015; DOI: 10.3171/2015.5.JNS15581. 
There are several management options for patients who receive subtotal adenoma resections. For minimal adenoma remnant without clear evidence of compression of the optic apparatus, expectant management with regular clinical and radiographic follow-up has been adopted as a reasonable approach. However, in the case of residual and recurrent adenomas with a high likelihood of continued growth, repeat transsphenoidal surgery or stereotactic radiosurgery are both acceptable treatment options. Aggressive debulking of invasive, laterally extending adenomas involving the cavernous sinus beyond the medial wall has previously been reported, but can pose undue risk to neurological and endocrine function. Stereotactic radiosurgery is a safe, viable management option for patients who receive subtotal resections and patients with recurrent nonfunctioning macroadenomas, or, less commonly, as an initial treatment for patients with high surgical comorbidities. ${ }^{4,23-26,28,33,35,37,45,47-49,51-53,61,65}$ Stereotactic radiosurgery helps reduce some of the risks of conventional radiotherapy, including hypopituitarism, radiation-induced tumors, carotid stenosis, and stroke, as well as neurocognitive side effects. ${ }^{1,30,38,39,56}$

Gamma Knife radiosurgery (GKRS) is highly effective at preventing radiographic progression of residual and recurrent adenomas. Most large radiosurgical series demonstrate a tumor control rate approaching $90 \% .{ }^{45,52} \mathrm{In}$ a more recent multicenter study of 512 patients, overall tumor control was achieved in $93.4 \%$ of patients at the lastfollow-up with actuarial tumor control rates of $98 \%, 95 \%$, $91 \%$, and $85 \%$ at $3,5,8$, and 10 years after radiosurgery, respectively. ${ }^{53}$ Despite the efficacy of stereotactic radiosurgery, there remains a lack of general consensus on its role in the spectrum of treatment. Specifically, it remains unclear whether GKRS should be used early to treat residual adenoma or after a set period of clinical and radiographic observation during which adenoma growth has been prospectively demonstrated.

Among the reasons that radiosurgery is not routinely performed early after surgery to treat residual adenoma is the concern for radiation-induced endocrinopathy. Older fractionated radiotherapy series have reported incidences of new endocrinopathy ranging from $25 \%$ to $40 \%$. 17,20,37,49 However, more recent multicenter radiosurgery series have reported a lower incidence of new or worsened hypopituitarism after radiosurgery that is closer to $20 \%$, with thyroid and cortisol deficiencies reported as the most common postradiosurgical endocrinopathies. ${ }^{53}$ Given the high incidence of adenoma progression after subtotal resection over time and the efficacy of radiosurgery for preventing tumor progression with a relatively low incidence of new endocrinopathy, the present study examines the potential utility of GKRS performed shortly after transsphenoidal surgery. This study serves to further define the optimal treatment strategies following subtotal resection of nonfunctioning pituitary adenomas and the attendant risks of an additional procedure versus expectant management.

\section{Methods \\ Data Collection}

This study was approved by the University of Virginia Institutional Review Board. All patients who received
GKRS for residual nonfunctioning pituitary macroadenomas after subtotal transsphenoidal resection during the period from 1996 to 2013 were evaluated for inclusion in this study. In total, 206 patients received GKRS for residual tumor, but 142 patients were excluded due to inadequate endocrine and/or radiographic follow-up ( $\mathrm{n}=$ 60 ), resection performed elsewhere or inadequate preoperative information $(n=51)$, limited follow-up between resection and radiosurgery $(\mathrm{n}=27)$, craniotomy instead of transsphenoidal resection $(\mathrm{n}=2)$, unclear diagnosis ( $=1)$, or GKRS performed as an initial treatment $(\mathrm{n}=1)$. Patients who presented with hormonally active tumors were excluded. The final analysis includes 64 patients. All included patients had demonstrable residual adenoma at the conclusion of the resection that preceded GKRS. Data were collected from a retrospective chart review, including patient demographics, presenting symptoms, preoperative and postoperative radiographic imaging and reports, operative notes, treatment data, histological reports, and follow-up clinic reports.

\section{Patient Evaluation}

All patients underwent preoperative imaging (MRI or CT) and neurological and endocrinological evaluations. Serum cortisol, free thyroxine, thyroid-stimulating hormone, luteinizing hormone, follicle-stimulating hormone, testosterone (in men), prolactin, growth hormone, and insulin-like growth factor-I (IGF-1) levels were tested preoperatively. Patients with evidence of vision loss or chiasm compression were referred to an ophthalmologist for formal visual field testing. Nonfunctioning macroadenomas were defined by 1) the presence of a sellar mass greater than $1 \mathrm{~cm}$ in dimension (prior to transsphenoidal surgery); 2) an absence of elevated serum prolactin $(<200$ $\mathrm{ng} / \mathrm{ml}$ ), adrenocorticotropic hormone, growth hormone, and IGF-1; and 3) an absence of the clinical and biochemical features of Cushing's disease or acromegaly. Patients with low cortisol or thyroxine levels were treated with oral medications. Neurological and endocrine evaluations occurred daily while hospitalized at 8 weeks after transsphenoidal surgery and annually thereafter. Prior to GKRS, patients also underwent comprehensive neurological and endocrine evaluations. Patients underwent stereotactic MRI or CT on the day of GKRS. Clinical and radiographic information from this visit served as the baseline data to which follow-up information was compared.

\section{Clinical and Radiographic Follow-Up}

Patients were followed up clinically and with radiographic imaging of the sella (typically MRI) at routine intervals with imaging every 6 months for the 1st year and then annually until 5 years after radiosurgery. After 5 years, patients typically underwent follow-up at annual or biannual intervals thereafter. Follow-up visits consisted of neurological and ophthalmological assessments to evaluate new or progressive neurological deficits. Imaging studies were used to evaluate tumor response to treatment, and endocrine testing was matched to these follow-up time points. All neuroimaging studies were independently reviewed by a neurosurgeon and a neuroradiologist at the University of Virginia Health System. Clinical and radio- 
graphic outcomes were determined 2 months postoperatively, just before GKRS, and again by the last available examination. A change in tumor size was defined by $15 \%$ or greater increase or decrease in tumor volume. ${ }^{54}$ Adenomas with less than $15 \%$ change in size were deemed stable. New endocrinopathy was defined by laboratory hormonal evaluation and a subsequent physician recommendation for medical hormone replacement therapy.

\section{Radiosurgical Technique}

All GKRS procedures were performed at the University of Virginia Health System. The radiosurgical techniques have been previously described. . $^{51,55,62}$ The procedure was performed using the Leksell Gamma Unit (Elekta Instruments) model U before 2001 and model C thereafter. GammaPlan software (Elekta) was used for treatment planning. Pre- and postcontrast T1-weighted MR images were obtained with a slice thickness of $1.2 \mathrm{~mm}$. Fat-saturated stereotactic imaging was also performed. Placement of a stereotactic Leksell G-frame was performed in the operating room under local anesthesia and additional intravenous conscious sedation as needed. All patients were monitored by an anesthesiologist. Following frame placement, highresolution stereotactic MRI was performed for treatment planning. Pre- and postcontrast thin-slice $(1 \mathrm{~mm})$ axial and coronal plane images through the sella were obtained. Fat suppression imaging was performed. Thin-slice stereotactic CT scans were obtained in the rare case of medical contraindications to MRI. Stereotactic radiosurgery and dose planning were then performed in consultation with a neurosurgeon, radiation oncologist, and medical physicist. ${ }^{52,56}$

\section{Statistical Analysis}

Statistical analyses were obtained using the chi-square and Fisher exact tests. Statistics of means were carried out using the unpaired Student t-test, both with and without equal variance (Levene test) as necessary. Kaplan-Meier curves were plotted for survival and progression-free survival using the dates of first resection, radiosurgery, follow-up imaging, and last clinical follow-up. For all statistical tests, a $\mathrm{p}$ value $\leq 0.05$ was considered significant.

\section{Results}

\section{Patient Demographics and Presenting Symptoms}

A total of 64 patients met the study criteria and were included in the analysis. Patients were stratified based on the interval between resection and radiosurgery into early ( $\leq 6$ months; $\mathrm{n}=32$ ) and late ( $>6$ months; $\mathrm{n}=32$ ) cohorts. The average age at presentation was 50.8 years, with a slightly higher age at resection (51.9 years) and Gamma Knife treatment (53.7 years). Fifty percent of the patients in each group $(n=16)$ underwent more than 1 surgical resection before undergoing GKRS. Three patients $(9.4 \%)$ in the early cohort and 5 patients in the late cohort (15.6\%) underwent 3 resections. Patients were followed up for a median radiographic period of 68.5 months (range 10.8218.9 months) (Table 1).

Among the 64 total patients, all but 2 (both in the early cohort with incidental findings from unrelated brain imaging) presented either with 1 or a constellation of symptoms consistent with a diagnosis with pituitary adenoma, which was confirmed by neuroimaging. Across all patients, the most common presenting symptom was a visual deficit (n $=45 ; 70.3 \%$ ). The symptoms at presentation were fatigue/ weakness $(n=31 ; 48.4 \%)$, headache $(n=22 ; 34.4 \%)$, and sexual dysfunction $(\mathrm{n}=21 ; 32.8 \%)$. Endocrine function at presentation was determined by a combination of serum hormone levels $(\mathrm{n}=24)$ and/or patient medications $(\mathrm{n}=$ 40). Twenty-five patients (39.1\%) presented with prior endocrinopathy. Of note, 1 female patient was determined to have low gonadal function and was receiving hormone replacement at presentation, but she also had other endocrine abnormalities that were deemed panhypopituitarism. There was no significant difference in presenting symptoms or endocrine function between the 2 groups (Table 1).

\section{Tumor Characteristics}

At the time of the initial presentation for resection, all tumors were macroadenomas and were classified by size, volume, involvement and/or invasion of the surrounding structures, and histopathology (Table 2). Preoperatively, most tumors measured 2 to $4 \mathrm{~cm}$ in the maximum diameter ( $\mathrm{n}=18$ in early cohort; $\mathrm{n}=20$ in late cohort), and the average tumor volume was $8.4 \mathrm{~cm}^{3}$ (range $1.0-32.2 \mathrm{~cm}^{3}$ ) in the early cohort and $11.3 \mathrm{~cm}^{3}$ (range $1.0-115.0 \mathrm{~cm}^{3}$ ) in the late cohort. Fourteen $(43.8 \%)$ tumors were larger than $10 \mathrm{~cm}^{3}$ in the early cohort versus $12(37.5 \%)$ in the late cohort. In 46 (71.9\%) of 64 patients, the tumor had a suprasellar component, and 49 patients (76.6\%) exhibited cavernous sinus involvement. There was no statistically significant difference between the early (75\%) and late (78.1\%) cohorts with respect to cavernous sinus involvement $(\mathrm{p}=1.00)$. Histologically, null cell adenomas were most common $(n=23 ; 35.9 \%)$, and significantly more patients in the late cohort had these tumors $(\mathrm{n}=16)$ compared with the early cohort $(\mathrm{n}=7)(\mathrm{p}=0.036)$. Gonadotrophic (32.8\%) and silent corticotrophic tumors (31.2\%) were the next most common types of macroadenoma.

\section{Surgical Outcomes}

After transsphenoidal surgery, tumor volumes were reduced by an average of $82.8 \%\left(6.9 \mathrm{~cm}^{3}\right)$ and $87.7 \%(9.9$ $\mathrm{cm}^{3}$ ) in the early and late cohorts, respectively. A majority of patients $(\mathrm{n}=49 ; 76.6 \%)$ exhibited a residual tumor that was identified on radiographic imaging studies at 2 months after surgery, which was consistent across groups $(\mathrm{p}=1.00)$. Average residual tumor volume at 2 months following surgery was $1.94 \mathrm{~cm}^{3}$ in the early group $(\mathrm{n}=$ $26)$ and $1.95 \mathrm{~cm}^{3}$ in the late group $(\mathrm{n}=23)$, which was not a significant difference $(\mathrm{p}=0.99)$. Six $(25 \%)$ of 24 total patients experienced resolution of the preoperative endocrinopathies. There was no significant difference in the resolution of preexisting endocrinopathies $(p=1.00)$ or the development of new endocrinopathies after surgery across groups $(\mathrm{p}=1.00)$ (Table 3$)$.

\section{GKRS Parameters}

In the early cohort, the average time to radiosurgery from surgical resection was 3.2 months (range 1.5-5.3 months). In the late cohort, the average time to radio- 
TABLE 1. Patient demographics

\begin{tabular}{|c|c|c|c|}
\hline Variable & Early GKRS ( $\leq 6 \mathrm{mos}$ ) & Late GKRS (>6 mos) & $\mathrm{p}$ Value \\
\hline Patients, n (\%) & $32(50.0 \%)$ & $32(50.0 \%)$ & \\
\hline Male, n (\%) & $19(29.7 \%)$ & $24(37.5 \%)$ & 0.29 \\
\hline Female, $\mathrm{n}(\%)$ & $13(20.3 \%)$ & $8(12.5 \%)$ & \\
\hline Mean age at presentation, yrs (SD) & $51.6(13.3)$ & $49.9(14.6)$ & 0.63 \\
\hline Mean age at surgery, yrs (SD) & $52.6(13.1)$ & $51.2(14.9)$ & 0.69 \\
\hline Mean age at GKRS, yrs (SD) & $53.7(13.2)$ & $53.7(15.0)$ & 1.00 \\
\hline Mean clinical FU length, mos (range) & $50.1(7.8-189.4)$ & $79.8(18.2-230.2)$ & \\
\hline Mean FU length, mos (range) & $57.2(10.8-201.3)$ & $84.5(21.6-218.9)$ & \\
\hline \multicolumn{4}{|l|}{ Presenting symptoms, n (\%) } \\
\hline Visual deficit & $21(65.6 \%)$ & $24(75.0 \%)$ & 0.42 \\
\hline Headache & $11(34.4 \%)$ & $11(34.4 \%)$ & 1.00 \\
\hline Endocrinopathy & $11(34.4 \%)$ & $13(40.6 \%)$ & 0.80 \\
\hline Fatigue/weakness & $16(50.0 \%)$ & $15(46.9 \%)$ & 1.00 \\
\hline Sexual dysfunction & $9(28.1 \%)$ & $12(37.5 \%)$ & 0.60 \\
\hline Incidental & $2(6.3 \%)$ & $0(0.0 \%)$ & 0.49 \\
\hline Recurrent (previous TSR)§ & $16(50.0 \%)$ & $16(50.0 \%)$ & 1.00 \\
\hline \multicolumn{4}{|l|}{ Endocrine function, $\mathrm{n}(\%)$} \\
\hline Hypogonadism, male & $0(0.0 \%)$ & $3(9.4 \%)$ & 0.24 \\
\hline Hypogonadism, female* & $0(0.0 \%)$ & $0(0.0 \%)$ & 1.00 \\
\hline Hypocortisolism† & $0(0.0 \%)$ & $0(0.0 \%)$ & 1.00 \\
\hline Hypothyroidism & $5(15.6 \%)$ & $3(9.4 \%)$ & 0.71 \\
\hline Panhypopituitarism $\ddagger$ & $6(18.8 \%)$ & $7(21.9 \%)$ & 1.00 \\
\hline \multicolumn{4}{|c|}{$\begin{array}{l}\text { FU = follow-up; TSR = transsphenoidal resection. } \\
\text { * One female patient had low gonadal levels and was on replacement, but was included with other patients with panhypopituitarism. } \\
\text { † Nine patients had low cortisol levels and were on replacement, but were included with other patients with panhypopituitarism. } \\
\text { † Includes } 2 \text { or more endocrine abnormalities. } \\
\S \text { Number of patients who received repeat TSR per group is shown. }\end{array}$} \\
\hline
\end{tabular}

surgery from surgical resection was 27.6 months (range 6.6-77.1 months). In the late cohort, 11 (34.4\%) patients received treatment within 6 to 12 months after subtotal resection, $4(12.5 \%)$ patients received treatment within 12 to 24 months, and $17(53.1 \%)$ patients received treatment longer than 24 months after subtotal resection. The median maximum dose to the tumor was $32 \mathrm{~Gy}$ in both cohorts (range 10-40 Gy). The median tumor margin dose was 16 Gy (range 5-20 Gy). The average target volume was numerically larger in the late cohort $\left(5.6 \mathrm{~cm}^{3}\right)$ compared with the early cohort $\left(4.5 \mathrm{~cm}^{3}\right)$, but this was not significantly different cross groups $(\mathrm{p}=0.17)$. The maximum dose to the visual pathways (optic apparatus) was typically limited to an average of 4.2 Gy (Table 4). Whenever necessary, shielding was used to limit the radiation dose to the optic apparatus.

\section{Radiological Outcome}

Patients in the early cohort had an average of 57.2 months of radiographic follow-up (range 10.8-201.3 months). Patients in the late cohort had an average of 84.5 months of radiographic follow-up (range 21.6-218.9 months). In the early cohort, $11(34.4 \%)$ patients underwent more than 5 years and $4(12.5 \%)$ patients underwent more than 10 years of radiographic follow-up. In the late cohort, $23(71.9 \%)$ patients underwent longer than 5 years and 4 (12.5\%) patients underwent longer than 10 years of radiographic follow-up. Over this period, a significantly higher proportion $(n=27$; $84.4 \%$ ) of patients in the late cohort exhibited residual tumor that was visible on imaging at the last follow-up compared with patients in the early cohort $(\mathrm{n}=18 ; 56.3 \%)(\mathrm{p}$ $=0.027)$. The vast majority $(91.1 \%)$ of all residual tumors across both groups (94.4\% in the early group and $88.9 \%$ in the late group) remained stable in size over the postradiosurgical follow-up period. However, significantly more patients in the early cohort experienced the resolution of postoperative residual tumor $(34.6 \%)$ than patients in the late cohort $(8.7 \%)(p=0.042)$. Tumor growth, which was defined as a greater than $15 \%$ increase in tumor volume, was exhibited in 1 patient $(5.6 \%)$ in the early cohort and 3 patients $(11.1 \%)$ in the late cohort $(\mathrm{p}=0.639)$. Two patients $(6.3 \%)$ in the early cohort exhibited growth or new residual tumor at the last follow-up imaging versus 9 patients $(28.1 \%)$ in the late cohort $(\mathrm{p}=0.043)$ (Table 5). Two patients, both in the late cohort, underwent repeat resection 
TABLE 2. Preoperative tumor characteristics

\begin{tabular}{lccc}
\hline \multicolumn{1}{c}{ Variable } & $\begin{array}{c}\text { Early GKRS } \\
(\leq 6 \mathrm{mos})\end{array}$ & $\begin{array}{c}\text { Late GKRS } \\
(>6 \mathrm{mos})\end{array}$ & $\mathrm{p}$ Value \\
\hline Maximum tumor diameter, cm & & & \\
\hline $1-1.9, \mathrm{n}(\%)$ & $7(21.9 \%)$ & $5(15.6 \%)$ & 0.75 \\
\hline $2-2.9, \mathrm{n}(\%)$ & $9(28.1 \%)$ & $11(34.4 \%)$ & 0.79 \\
\hline $3-4.0, \mathrm{n}(\%)$ & $9(28.1 \%)$ & $9(28.1 \%)$ & 1.00 \\
\hline$>4.0, \mathrm{n}(\%)$ & $7(21.9 \%)$ & $7(21.9 \%)$ & 1.00 \\
\hline Average tumor vol, $\mathrm{cm}^{3}$ & & & \\
\hline$<10, \mathrm{n}(\%)$ & $18(56.3 \%)$ & $20(62.5 \%)$ & 0.80 \\
\hline$>10, \mathrm{n}(\%)$ & $14(43.8 \%)$ & $12(37.5 \%)$ & \\
\hline Suprasellar involvement, $\mathrm{n}(\%)$ & $24(75.0 \%)$ & $22(68.8 \%)$ & 0.78 \\
\hline Cavernous sinus invasion, $\mathrm{n}(\%)$ & $24(75.0 \%)$ & $25(78.1 \%)$ & 1.00 \\
\hline Bilateral cavernous sinus inva- & $4(12.5 \%)$ & $6(18.8 \%)$ & \\
sion, $\mathrm{n}(\%)$ & & & \\
\hline Histopathology, $\mathrm{n}(\%)$ & & & \\
\hline Null cell adenoma & $7(21.9 \%)$ & $16(50.0 \%)$ & 0.036 \\
\hline Gonadotroph & $14(43.8 \%)$ & $7(21.9 \%)$ & 0.11 \\
\hline Silent corticotroph & $11(34.4 \%)$ & $9(28.1 \%)$ & 0.79 \\
\hline Thyrotroph & $0(0.0 \%)$ & $0(0.0 \%)$ & 1.00 \\
\hline Somatotroph & $0(0.0 \%)$ & $0(0.0 \%)$ & 1.00 \\
\hline
\end{tabular}

after GKRS (1 patient due to interval tumor growth and 1 patient on an elective basis for optic nerve decompression).

\section{Endocrine Outcome}

At the time of GKRS, $41(64.1 \%)$ of 64 patients had some degree of pituitary insufficiency, with a similar number across groups $(\mathrm{p}=1.00)$. A significantly higher proportion of patients in the late cohort without endocrinopathy before GKRS developed new endocrinopathies over the follow-up period: $2(16.7 \%)$ of 12 patients in the early cohort compared with 7 (63.6\%) of 11 patients in the late cohort $(\mathrm{p}=0.036)$. Of 9 total patients who developed new endocrinopathies, 1 case (in the late cohort) was attributed to tumor growth, 4 cases to reoperation, and 4 cases to radiosurgery. When considering all patients with endocrinopathy at the last follow-up, a significantly higher number of patients in the late cohort exhibited endocrinopathy secondary to tumor growth generally before GKRS ( 8 of 28 patients) compared with the early cohort ( 0 of 20 patients) $(\mathrm{p}=0.014)$. There were no significant differences in endocrinopathy secondary to reoperation or radiosurgery across groups. In the early group, radiationassociated pituitary insufficiency developed in 1 of 2 patients with completely new endocrinopathies. In the late group, radiation-associated pituitary insufficiency developed in 3 of 7 (42.9\%) patients with completely new endocrinopathies. In total, a significantly higher proportion of patients in the late cohort (87.5\%) exhibited endocrinopathy at the last clinical follow-up compared with $62.5 \%$ in the early cohort $(\mathrm{p}=0.041)$ (Fig. 1). These included only 4 $(12.5 \%)$ new cases (by type, not patient) of endocrinopathy in the early cohort versus $12(37.5 \%)$ in the late cohort $(\mathrm{p}$ $=0.041)($ Table 5).

The resolution of endocrine dysfunction was further
TABLE 3. Surgical treatment

\begin{tabular}{llll}
\hline \multicolumn{1}{c}{ Variable } & \multicolumn{1}{c}{$\begin{array}{c}\text { Early GKRS } \\
(\leq 6 \text { mos })\end{array}$} & $\begin{array}{c}\text { Late GKRS } \\
(>6 \text { mos })\end{array}$ & $\begin{array}{c}\mathrm{p} \\
\text { Value }\end{array}$ \\
\hline Preop tumor vol, $\mathrm{cm}^{3}$ & 8.37 & 11.30 & \\
\hline Postop tumor vol, $\mathrm{cm}^{3}$ & 1.44 & 1.39 & \\
\hline $\begin{array}{l}\text { Reduction size, } \mathrm{cm}^{3} \\
\text { (\% change) }\end{array}$ & $-6.92(-82.8 \%)$ & $-9.91(-87.7 \%)$ & \\
\hline $\begin{array}{l}\text { Average residual tumor vol, } \\
\mathrm{cm}^{3}\end{array}$ & 1.94 & 1.95 & 0.99 \\
\hline Preop endocrinopathy, $\mathrm{n}(\%)$ & $11(34.4 \%)$ & $13(40.6 \%)$ & 0.80 \\
\hline $\begin{array}{l}\text { Postop endocrinopathy, } \\
\mathrm{n}(\%)\end{array}$ & $20(62.5 \%)$ & $21(65.6 \%)$ & 1.00 \\
\hline Resolved, $\mathrm{n}$ (\%) & & & \\
\hline Hypogonadism, male & 0 & $3(23.1 \%)$ & 1.00 \\
\hline Hypogonadism, female & 0 & 2 & \\
\hline Hypocortisolism & 0 & 0 & \\
\hline Panhypopituitarism & 1 & 0 & \\
\hline Hypothyroidism & 2 & 0 & \\
\hline New, $\mathrm{n}$ (\%) $\dagger$ & $12(37.5 \%)$ & $11(34.4 \%)$ & \\
\hline Hypogonadism, male & 2 & 1 & \\
\hline Hypogonadism, female & 1 & 0 & \\
\hline Hypocortisolism & 3 & 0 & \\
\hline $\begin{array}{l}\text { Panhypopituitarism } \\
\text { Hypothyroidism }\end{array}$ & 4 & 2 & \\
\hline
\end{tabular}

* Percentages are based on the number of patients with preoperative endocrinopathy.

$\dagger$ Percentages are based on the total number of patients in the group.

analyzed by the type of endocrinopathy, including hypogonadism, hypocortisolism, hypothyroidism, and panhypopituitarism. One female patient with hypogonadism and 3 patients with hypocortisolism had resolution of hypopituitarism in the early cohort. In the late cohort, 4 male patients with hypogonadism, 2 patients with hypocortisolism, 2 patients with hypothyroidism, and 4 patients with panhypopituitarism showed evidence of clinical resolution. There was no significant difference in the resolution of symptoms across groups $(\mathrm{p}=1.00)$.

TABLE 4. GKRS treatment parameters

\begin{tabular}{lccc}
\hline & $\begin{array}{c}\text { Early GKRS } \\
(\leq 6 \text { mos })\end{array}$ & $\begin{array}{c}\text { Late GKRS } \\
(>6 \text { mos })\end{array}$ & $\begin{array}{c}p \\
\text { Value }\end{array}$ \\
\hline $\begin{array}{l}\text { Mean margin dose, } \\
\text { Gy (range) }\end{array}$ & $16.1(15.0-18.0)$ & $15.6(5.0-20.0)$ & 0.27 \\
\hline Max dose, Gy (range) & $32.1(30.0-36.1)$ & $30.9(10.0-40.0)$ & 0.21 \\
\hline Target vol, cm $^{3}$ (range) & $4.5(0.8-13.2)$ & $5.6(0.5-14.9)$ & 0.17 \\
\hline $\begin{array}{l}\text { Max dose to optic } \\
\text { chiasm, Gy (range) }\end{array}$ & $6.3(2.3-11.0)$ & $6.6(3.0-10.6)$ & 0.58 \\
\hline $\begin{array}{l}\text { Max dose to optic tract, } \\
\text { Gy (range) }\end{array}$ & $4.0(1.5-8.1)$ & $4.4(1.7-11.6)$ & 0.33 \\
\hline $\begin{array}{l}\text { Max dose to optic nerve, } \\
\text { Gy (range) }\end{array}$ & $7.4(2.1-10.4)$ & $7.1(4.0-10.4)$ & 0.64 \\
\hline
\end{tabular}

Max = maximum. 
TABLE 5. Outcomes

\begin{tabular}{|c|c|c|c|}
\hline Variable & Early GKRS ( $\leq 6 \mathrm{mos})$ & Late GKRS (>6 mos) & $\mathrm{p}$ Value \\
\hline Residual tumor at last FU, $\mathrm{n}(\%)^{*}$ & $18(56.3 \%)$ & $27(84.4 \%)$ & 0.027 \\
\hline Tumor stable & $17(94.4 \%)$ & $24(88.9 \%)$ & \\
\hline Tumor growth & $1(5.6 \%)$ & $3(11.1 \%)$ & \\
\hline Growth or new residual & $2(6.3 \%)$ & $9(28.1 \%)$ & 0.043 \\
\hline Pre-GKRS endocrinopathy, $\mathrm{n}(\%) \dagger$ & $20(62.5 \%)$ & $21(65.6 \%)$ & 1.00 \\
\hline Fully resolved endocrinopathy & 2 & 0 & 0.23 \\
\hline Pre-GKRS no endocrinopathy, $n(\%)$ & $12(37.5 \%)$ & $11(34.4 \%)$ & 1.00 \\
\hline Completely new endocrinopathy & 2 & 7 & 0.036 \\
\hline Post-GKRS endocrinopathy, $n$ (\%) $\ddagger$ & $20(62.5 \%)$ & $28(87.5 \%)$ & 0.041 \\
\hline Secondary to tumor growth & 0 & 8 & 0.014 \\
\hline Secondary to reoperation§ & 15 & 16 & 0.24 \\
\hline Secondary to radiosurgery & 5 & 3 & 0.25 \\
\hline Unknown & 0 & 1 & 1.00 \\
\hline Completely new endocrinopathy, $\mathrm{n}(\%) \Uparrow$ & $2(16.7 \%)$ & $7(63.6 \%)$ & 0.036 \\
\hline Secondary to tumor growth & 0 & 1 & 1.00 \\
\hline Secondary to reoperation & 1 & 3 & 1.00 \\
\hline Secondary to radiosurgery & 1 & 3 & 1.00 \\
\hline New, $n(\%) \S$ & $4(12.5 \%)$ & $12(37.5 \%)$ & \\
\hline Hypogonadism, male & 0 & 4 & \\
\hline Hypogonadism, female & 1 & 0 & \\
\hline Hypocort & 0 & 2 & \\
\hline Panhypopit & 2 & 4 & \\
\hline Hypothyroid & 0 & 2 & \\
\hline GH deficient & 1 & 0 & \\
\hline \multicolumn{4}{|c|}{$\begin{array}{l}\text { Hypocort = hypocortisolism; panhypopit = panhypopituitarism; hypothyroid = hypothyroidism; GH = growth hormone. } \\
\text { * Number of patients in each group with residual tumor at the last radiographic follow-up (e.g., } 18 \text { of } 32 \text { patients and } 27 \text { of } 32 \text { patients, respec- } \\
\text { tively). } \\
\dagger \text { Same as postoperative endocrinopathy. } \\
\text { † Percentage of all patients in the group. } \\
\text { § Five patients in the late GKRS group developed endocrinopathy after the first TSR, not a repeat operation. } \\
\text { ๆ Percentage of patients with pre-GKRS, not endocrinopathy. }\end{array}$} \\
\hline
\end{tabular}

\section{Discussion}

Pituitary adenomas represent common benign lesions that are found in approximately $10 \%$ to $30 \%$ of the general population. ${ }^{12,60}$ Nonfunctioning pituitary adenomas are typically slow-growing, hormonally quiescent tumors that can often expand significantly in size before symptoms manifest. While these tumors are not characteristically malignant, hormonally inactive adenomas can develop into large macroadenomas and subsequently disturb normal pituitary gland function by mass effect. Transsphenoidal surgery can effectively and completely remove many nonfunctioning pituitary adenomas; however, tumors invading laterally into the cavernous sinus beyond the medial wall render total resection difficult and potentially risky. ${ }^{44}$ GKRS has emerged as a highly effective treatment for residual or progressively growing nonfunctioning pituitary macroadenomas when gross-total resection cannot be achieved with surgery alone. Despite recent advances in the breadth and depth of available treatment modalities, the cumulative morbidity over a patient's lifetime associated with both of these treatments can be significant. ${ }^{56}$

In the current study, a matched cohort of 64 patients underwent transsphenoidal resection followed by GKRS for residual nonfunctioning pituitary macroadenomas. GKRS was performed as an adjunctive therapy for patients with residual adenomas that were known-based on serial postresection imaging - to be locally invasive in the cavernous sinus, bone, or dura, or when recurrence was clearly manifested by a return of symptoms and the tumor was considered unlikely to respond to additional resection. ${ }^{36}$ In the current study, all patients had residual tumor noted on direct intraoperative observation via microscopy and/or endoscopy at the time of resection. This time interval permits patients to recover from transsphenoidal resection, for postsurgical changes on MRI to subside, and more optimal imaging for GKRS targeting purposes. If there are equivocal changes on MRI at 2 to 3 months following surgery, then patients are typically placed into routine follow-up care with another brain MRI scheduled in 3 to 6 months. Thus, the early ( $\leq 6$ months) and late ( $>6$ months) dichotomy of the radiosurgical cohorts was a natural phenomenon resulting from our clinical care paradigm.

One of the prominent findings in this study was the significant difference in the rate of tumor control. Over an average radiographic follow-up of 70.8 months, there 


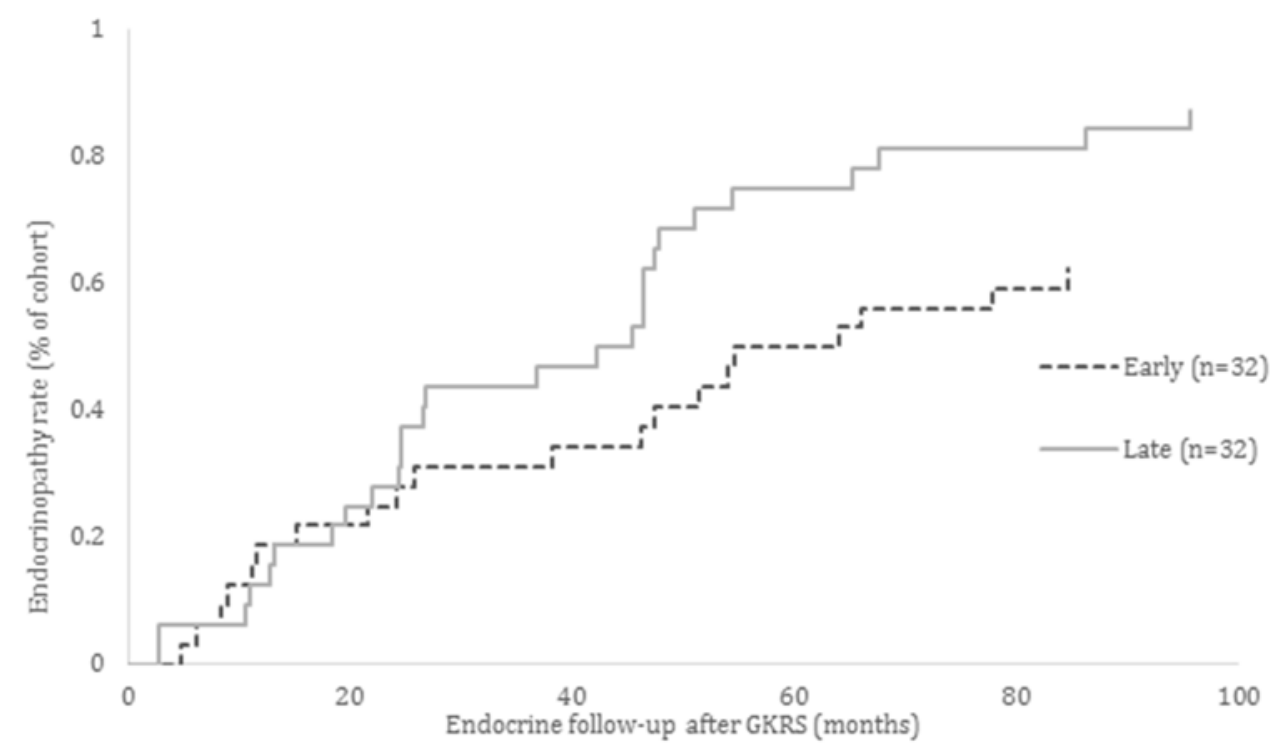

FIG. 1. Kaplan-Meier plot of the endocrinopathy rates after GKRS in patients in the early (dashed line) and late (solid line) cohorts.

was a greater risk of tumor progression after GKRS in the late treatment group. Significantly more patients in the late cohort exhibited residual tumor at the last follow-up $(\mathrm{p}=$ 0.027 ), as well as tumor growth or new tumor residual relative to postoperative imaging $(\mathrm{p}=0.043)$ A significantly higher proportion of patients in the early cohort exhibited the radiographic resolution of residual tumor after GKRS $(p=0.042)$. One possible explanation for this difference is that tumors in patients demonstrating adenoma growth are less likely to be controlled with GKRS secondary to an inherently more aggressive tumor biology than those patients treated earlier. Nonetheless, there is no sufficient evidence to conclude that the tumor biologies of the early and late cohorts differed, as patients in this study were not randomized and patients in the early cohort (treated less than 6 months from the time of resection) were presumably not given adequate time to demonstrate tumor growth for most adenomas. Alternatively, as volume is well known to affect the outcomes of stereotactic radiosurgery, an adenoma with a larger volume may simply be less effectively controlled. The average tumor volume treated in the late cohort was slightly higher (by $\left.1.1 \mathrm{~cm}^{3}\right)$, but there was no statistically significant difference $(\mathrm{p}=0.17)$.

Subtotal resection without adjuvant treatment has been shown to result in recurrence rates ranging from $50 \%$ to $60 \%$ within 10 years of surgery. ${ }^{9,22,34,43,46,48}$ In a recent metaanalysis of the natural history of nonfunctioning pituitary adenomas, the incidence of growth in macroadenomas was reportedly 12.53 per 100 person-years..$^{18}$ Two years prior, O'Sullivan et al. found that $33.5 \%$ of 159 patients with nonfunctioning adenomas who underwent resection, but not postoperative radiation therapy or radiosurgery, demonstrated evidence of recurrence or growth at a median follow-up of 4.1 years (range 1-20.7 months). The 5- and 10 -year actuarial rates of recurrence or growth of residual adenoma were $24.4 \%$ and $51.5 \%$, respectively. ${ }^{43}$ Other reports of surgically treated nonfunctioning adenomas suggest a 10-year rate of recurrence ranging from $19 \%$ to $78 \%$ after resection..$^{11,12,43,46,59}$ Given this high rate of progression in a 10-year period, radiosurgery has been recommended for patients with aggressive neuropathological attributes and younger patients with recurrent or residual tumors. ${ }^{53}$

Stereotactic radiosurgery has become a common adjuvant treatment for patients with recurrent or residual nonfunctioning pituitary adenomas. A summary of previously reported studies of stereotactic radiosurgery for nonfunctioning pituitary adenomas has been reproduced in Table $6.4,14,17,20,23-26,28,29,33,35,37,40,41,45,47-51,53,56,61,63,65$ While stereotactic radiosurgery confers a high rate of tumor control (approximately $90 \%$ ) and a low rate of neurological deficits, the promising results of adjuvant GKRS are largely byproducts of single-center retrospective studies. ${ }^{4,17,20,23-26,28 \text {, }}$ 29,33,35,37,41,45,47-49,51,55,61,65 More recently, a large-scale multicenter study proposed a strong benefit-to-risk profile of GKRS for patients with recurrent or residual growing nonfunctioning pituitary adenomas.$^{53}$ Despite such findings, a prominent challenge remains in establishing the optimal role and timing for GKRS during the postoperative period.

The prospect that radiosurgery plays an important complementary role to resection is further supported by the high reported rates of tumor control after GKRS. A recent series of 140 consecutive patients with nonfunctioning pituitary macroadenomas treated with GKRS at the University of Virginia Health System demonstrated an overall tumor control rate of $90 \%$ and an actuarial 5-year progression-free survival rate of $97 \%$. The investigators demonstrated that tumor control was directly related to radiosurgical treatment volume, highlighting the important utility of microsurgical resection prior to GKRS for macroadenomas. ${ }^{56}$ This sentiment was shared by Mingione et al. in 2006, who suggested a correlation between longer follow-up and a propensity for nonfunctioning pituitary macroadenomas to either grow or shrink. ${ }^{37}$ Comparable data of the long-term outcomes of GKRS for nonfunctioning adenomas from Park et al. noted a 90\% tumor control rate in 125 patients, with a mean follow-up of 62 months. ${ }^{45}$ Similarly, Gopalan et al. demonstrated a tumor control rate of $83 \%$ with a median follow-up of 95 months. ${ }^{20}$ Each of these studies noted that tumor volume was a predictor of new neurological decline, including delayed hypopituita- 
TABLE 6. Summary of the literature on stereotactic radiosurgery for nonfunctioning pituitary adenomas

\begin{tabular}{|c|c|c|c|c|c|}
\hline Authors \& Year & No. of Patients & $\begin{array}{c}\text { Mean/Median } \\
\text { Follow-Up (mos) }\end{array}$ & $\begin{array}{l}\text { Margin Dose } \\
\text { (Gy) }\end{array}$ & $\begin{array}{c}\text { Radiological } \\
\text { Tumor Control } \\
(\%)\end{array}$ & $\begin{array}{c}\text { Delayed } \\
\text { Hypopituitarism } \\
(\%)\end{array}$ \\
\hline Feigl et al., 2002 & 61 & 55.2 & 15.0 & 94.0 & 40.0 \\
\hline Sheehan et al., 2002 & 42 & 31.2 & 16.0 & 97.6 & 0.0 \\
\hline Wowra \& Stummer, 2002 & 30 & 57.7 & 16.0 & 93.3 & 10.0 \\
\hline Petrovich et al., 2003 & 52 & 34.0 & 15.0 & 100.0 & NR \\
\hline Losa et al., 2004 & 54 & 41.1 & 16.6 & 96.3 & 9.3 \\
\hline Muacevic et al., 2004 & 51 & 21.7 & 16.5 & 95.0 & 3.9 \\
\hline Kajiwara et al., 2005 & 14 & 32.1 & 12.6 & 92.9 & 7.1 \\
\hline Picozzi et al., 2005 & 51 & 40.6 & 16.5 & 96.1 & NR \\
\hline Iwai et al., 2005 & 28 & 36.4 & 12.3 & 93.0 & 7.0 \\
\hline Mingione et al., 2006 & 100 & 46.4 & 18.5 & 92.2 & 25.0 \\
\hline Voges et al., 2006 & 37 & 56.6 & 13.4 & 100.0 & 12.3 \\
\hline Liscák et al., 2007 & 140 & 60.0 & 20.0 & 100.0 & 1.4 \\
\hline Pollock et al., 2008 & 62 & 64.0 & 16.0 & 96.8 & 27.0 \\
\hline Höybye \& Rähn, 2009 & 23 & 78.0 & 20.0 & 100.0 & 0.0 \\
\hline Kobayashi, 2009 & 71 & 50.2 & NR & 96.7 & 8.2 \\
\hline Castro et al., 2010 & 14 & 42.0 & 12.5 & 100.0 & 0.0 \\
\hline Hayashi et al., 2010 & 43 & 36.0 & 18.2 & 100.0 & 0.0 \\
\hline Gopalan et al., 2011 & 48 & 95.0 & 18.4 & 83.0 & 39.0 \\
\hline Iwata et al., 2011 & 100 & 33.0 & $25^{*}$ & 98.0 & 2.0 \\
\hline Park et al., 2011 & 125 & 62.0 & 13.0 & 90.0 & 24.0 \\
\hline El-Shehaby et al., 2012 & 21 & 44.0 & 12.0 & 85.0 & 0.0 \\
\hline Runge et al., 2012 & 65 & 83.0 & 13.0 & 98.3 & 9.8 \\
\hline Starke et al., 2012 & 140 & 60.0 & 18.0 & 90.0 & 30.3 \\
\hline Wilson et al., 2012 & 51 & 50.0 & 14.0 & 100.0 & NR \\
\hline Sheehan et al., 2013 & 512 & 36.0 & 16.0 & 93.4 & 21.0 \\
\hline Minniti et al., 2015 & 68 & 75.0 & NR & $91.0 \dagger$ & 40.0 \\
\hline
\end{tabular}

rism. ${ }^{37,45,56}$ One explanation for tumor growth after GKRS might reside in the fact that larger adenomas in proximity to radiation-sensitive structures may limit the delivery of an ideal radiosurgical dose.

Despite the common progression of residual adenomas over time without further radiosurgical treatment, there exists a portion of patients with residual disease who do not have radiographic or clinical progression despite long follow-up times. It is difficult to predict which patients will have prolonged periods of stable tumor volume after subtotal resection alone and which patients will have progressive tumor growth within a short period of time after surgery. One of the principal arguments against early GKRS is that many residual adenomas may not progress and patients would be needlessly exposed to the potential complications of radiosurgery. Furthermore, under these circumstances, it remains unclear whether GKRS is as effective for treating actively growing pituitary adenomas compared with radiographically stable adenomas.

Another salient finding of the present study was the sig- nificant difference in the rates of endocrinopathy based on the interval between the last subtotal resection and GKRS. Over an average clinical follow-up of 65 months, there was a significantly higher occurrence of post-GKRS endocrinopathy in the late treatment cohort $(p=0.041)$. This difference was secondary to a significantly higher rate of tumor growth during the observation period prior to GKRS of the late treatment cohort $(p=0.014)$. Seventeen percent of patients without endocrinopathy in the early cohort developed new endocrinopathies following radiosurgery versus $64 \%$ in the late cohort $(p=0.036)$. The incidence of new hypopituitarism following transsphenoidal surgery for nonfunctioning tumors is reportedly as high as $30 \%$ in previous studies. $3,7,27,42$ Nomikos et al. reported a $1.4 \%$ rate of new endocrinological deficits after transsphenoidal surgery for nonfunctioning pituitary tumors. ${ }^{42}$

The present study has several strengths; chief among them is the number of patients and longitudinal nature of follow-up relative to other reports in the literature. Comprehensive radiographic, neurological, and endocrinologi- 
cal examinations were instrumental in describing the outcomes from resection and adjuvant radiosurgery. Although the current study represents a long mean follow-up duration, there are several weaknesses of the study that should be noted. This is a single-center analysis and thereby reflects the treatment bias of our institution and referral patterns. Furthermore, this is a retrospective analysis and is, therefore, inherently subject to bias. Larger patient pools could use propensity score matching techniques to reduce some biases. Similarly, patient bias may have resulted from some patients desiring early treatment versus others who preferred to be monitored for a longer period before deciding to proceed with radiosurgery. To help control for single-neurosurgeon selection bias, our institution has a multidisciplinary neuroendocrine group and biweekly case conferences. In fact, there was no tendency noted for bias for early versus late GKRS among the neurosurgeons who performed resections. Finally, the median follow-up period was 7.42 years; thus, we may have incompletely assessed delayed endocrine dysfunction and/or tumor control.

Further prospective and randomized studies would be necessary to definitively conclude that early treatment with radiosurgery reduces the rate of tumor progression and provides superior endocrine outcomes. Going forward, longitudinal follow-up studies with special emphasis on the timing of concomitant resection and radiosurgery in patients with pituitary macroadenomas will help further elucidate the natural history of surgically treated tumors.

\section{Conclusions}

Early GKRS appears to decrease the rate of radiographic and symptomatic progression of subtotally resected nonfunctioning pituitary macroadenomas compared with expectant management. Delaying radiosurgery may place the patient at increased risk for adenoma progression and endocrinopathy.

\section{References}

1. Brada M, Rajan B, Traish D, Ashley S, Holmes-Sellors PJ, Nussey S, et al: The long-term efficacy of conservative surgery and radiotherapy in the control of pituitary adenomas. Clin Endocrinol (Oxf) 38:571-578, 1993

2. Brochier S, Galland F, Kujas M, Parker F, Gaillard S, Raftopoulos C, et al: Factors predicting relapse of nonfunctioning pituitary macroadenomas after neurosurgery: a study of 142 patients. Eur J Endocrinol 163:193-200, 2010

3. Cappabianca P, Cavallo LM, Colao A, de Divitiis E: Surgical complications associated with the endoscopic endonasal transsphenoidal approach for pituitary adenomas. J Neurosurg 97:293-298, 2002

4. Castro DG, Cecílio SA, Canteras MM: Radiosurgery for pituitary adenomas: evaluation of its efficacy and safety. Radiat Oncol 5:109, 2010

5. Chandler WF, Schteingart DE, Lloyd RV, McKeever PE, Ibarra-Perez G: Surgical treatment of Cushing's disease. J Neurosurg 66:204-212, 1987

6. Chang EF, Zada G, Kim S, Lamborn KR, Quinones-Hinojosa A, Tyrrell JB, et al: Long-term recurrence and mortality after surgery and adjuvant radiotherapy for nonfunctional pituitary adenomas. J Neurosurg 108:736-745, 2008

7. Charalampaki P, Reisch R, Ayad A, Conrad J, Welschehold S, Perneczky A, et al: Endoscopic endonasal pituitary surgery: surgical and outcome analysis of 50 cases. J Clin Neurosci 14:410-415, 2007

8. Comtois R, Beauregard H, Somma M, Serri O, Aris-Jilwan $\mathrm{N}$, Hardy J: The clinical and endocrine outcome to transsphenoidal microsurgery of nonsecreting pituitary adenomas. Cancer 68:860-866, 1991

9. Dallapiazza RF, Grober Y, Starke RM, Laws ER Jr, Jane JA Jr: Long-term results of endonasal endoscopic transsphenoidal resection of nonfunctioning pituitary macroadenomas. Neurosurgery 76:42-53, 2015

10. Daly AF, Rixhon M, Adam C, Dempegioti A, Tichomirowa MA, Beckers A: High prevalence of pituitary adenomas: a cross-sectional study in the province of Liege, Belgium. J Clin Endocrinol Metab 91:4769-4775, 2006

11. Dekkers OM, Pereira AM, Roelfsema F, Voormolen JH, Neelis KJ, Schroijen MA, et al: Observation alone after transsphenoidal surgery for nonfunctioning pituitary macroadenoma. J Clin Endocrinol Metab 91:1796-1801, 2006

12. Dekkers OM, Pereira AM, Romijn JA: Treatment and followup of clinically nonfunctioning pituitary macroadenomas. $\mathbf{J}$ Clin Endocrinol Metab 93:3717-3726, 2008

13. Ebersold MJ, Laws ER Jr, Scheithauer BW, Randall RV: Pituitary apoplexy treated by transsphenoidal surgery. A clinicopathological and immunocytochemical study. J Neurosurg 58:315-320, 1983

14. El-Shehaby AM, Reda WA, Tawadros SR, Abdel Karim KM: Low-dose Gamma Knife surgery for nonfunctioning pituitary adenomas. J Neurosurg 117 Suppl:84-88, 2012

15. Ezzat S, Asa SL, Couldwell WT, Barr CE, Dodge WE, Vance ML, et al: The prevalence of pituitary adenomas: a systematic review. Cancer 101:613-619, 2004

16. Feigl GC, Bonelli CM, Berghold A, Mokry M: Effects of gamma knife radiosurgery of pituitary adenomas on pituitary function. J Neurosurg 97:415-421, 2002

17. Feigl GC, Pistracher K, Berghold A, Mokry M: Pituitary insufficiency as a side effect after radiosurgery for pituitary adenomas: the role of the hypothalamus. J Neurosurg 113 Suppl:153-159, 2010

18. Fernández-Balsells MM, Murad MH, Barwise A, GallegosOrozco JF, Paul A, Lane MA, et al: Natural history of nonfunctioning pituitary adenomas and incidentalomas: a systematic review and metaanalysis. J Clin Endocrinol Metab 96:905-912, 2011

19. Ferrante E, Ferraroni M, Castrignanò T, Menicatti L, Anagni M, Reimondo G, et al: Non-functioning pituitary adenoma database: a useful resource to improve the clinical management of pituitary tumors. Eur J Endocrinol 155:823-829, 2006

20. Gopalan R, Schlesinger D, Vance ML, Laws E, Sheehan J: Long-term outcomes after Gamma Knife radiosurgery for patients with a nonfunctioning pituitary adenoma. Neurosurgery 69:284-293, 2011

21. Greenman Y, Ouaknine G, Veshchev I, Reider-Groswasser II, Segev Y, Stern N: Postoperative surveillance of clinically nonfunctioning pituitary macroadenomas: markers of tumour quiescence and regrowth. Clin Endocrinol (Oxf) 58:763769,2003

22. Greenman Y, Stern N: How should a nonfunctioning pituitary macroadenoma be monitored after debulking surgery? Clin Endocrinol (Oxf) 70:829-832, 2009

23. Hayashi M, Chernov M, Tamura N, Nagai M, Yomo S, Ochiai T, et al: Gamma Knife robotic microradiosurgery of pituitary adenomas invading the cavernous sinus: treatment concept and results in 89 cases. J Neurooncol 98:185-194, 2010

24. Höybye C, Rähn T: Adjuvant Gamma Knife radiosurgery in non-functioning pituitary adenomas; low risk of long-term complications in selected patients. Pituitary 12:211-216, 2009 
25. Iwai Y, Yamanaka K, Yoshioka K: Radiosurgery for nonfunctioning pituitary adenomas. Neurosurgery 56:699-705, 2005

26. Iwata H, Sato K, Tatewaki K, Yokota N, Inoue M, Baba Y, et al: Hypofractionated stereotactic radiotherapy with $\mathrm{Cy}$ berKnife for nonfunctioning pituitary adenoma: high local control with low toxicity. Neuro Oncol 13:916-922, 2011

27. Jho HD, Carrau RL: Endoscopic endonasal transsphenoidal surgery: experience with 50 patients. J Neurosurg 87:44-51, 1997

28. Kajiwara K, Saito K, Yoshikawa K, Kato S, Akimura T, Nomura $\mathrm{S}$, et al: Image-guided stereotactic radiosurgery with the CyberKnife for pituitary adenomas. Minim Invasive Neurosurg 48:91-96, 2005

29. Kobayashi T: Long-term results of stereotactic gamma knife radiosurgery for pituitary adenomas. Specific strategies for different types of adenoma. Prog Neurol Surg 22:77-95, 2009

30. Langsenlehner T, Stiegler C, Quehenberger F, Feigl GC, Jakse G, Mokry M, et al: Long-term follow-up of patients with pituitary macroadenomas after postoperative radiation therapy: analysis of tumor control and functional outcome. Strahlenther Onkol 183:241-247, 2007

31. Laws ER Jr, Ebersold MJ, Piepgras DG: The results of transsphenoidal surgery in specific clinical entities, in Laws ER, Randall RV, Kern EB, et al. (eds): Management of Pituitary Adenomas and Related Lesions with Emphasis on Transsphenoidal Microsurgery. New York: Appleton-CenturyCrofts, 1982, pp 277-305

32. Laws ER Jr, Vance ML: Radiosurgery for pituitary tumors and craniopharyngiomas. Neurosurg Clin N Am 10:327336, 1999

33. Liscák R, Vladyka V, Marek J, Simonová G, Vymazal J: Gamma knife radiosurgery for endocrine-inactive pituitary adenomas. Acta Neurochir (Wien) 149:999-1006, 2007

34. Losa M, Mortini P, Barzaghi R, Ribotto P, Terreni MR, Marzoli SB, et al: Early results of surgery in patients with nonfunctioning pituitary adenoma and analysis of the risk of tumor recurrence. J Neurosurg 108:525-532, 2008

35. Losa M, Valle M, Mortini P, Franzin A, da Passano CF, Cenzato $\mathrm{M}$, et al: Gamma knife surgery for treatment of residual nonfunctioning pituitary adenomas after surgical debulking. J Neurosurg 100:438-444, 2004

36. Meij BP, Lopes MB, Ellegala DB, Alden TD, Laws ER Jr: The long-term significance of microscopic dural invasion in 354 patients with pituitary adenomas treated with transsphenoidal surgery. J Neurosurg 96:195-208, 2002

37. Mingione V, Yen CP, Vance ML, Steiner M, Sheehan J, Laws ER, et al: Gamma surgery in the treatment of nonsecretory pituitary macroadenoma. J Neurosurg 104:876-883, 2006

38. Minniti G, Gilbert DC, Brada M: Modern techniques for pituitary radiotherapy. Rev Endocr Metab Disord 10:135144, 2009

39. Minniti G, Jaffrain-Rea ML, Osti M, Cantore G, Enrici RM: Radiotherapy for nonfunctioning pituitary adenomas: from conventional to modern stereotactic radiation techniques. Neurosurg Rev 30:167-176, 2007

40. Minniti G, Scaringi C, Poggi M, Jaffrain Rea ML, Trillò G, Esposito V, et al: Fractionated stereotactic radiotherapy for large and invasive non-functioning pituitary adenomas: longterm clinical outcomes and volumetric MRI assessment of tumor response. Eur J Endocrinol 172:433-441, 2015

41. Muacevic A, Uhl E, Wowra B: Gamma knife radiosurgery for nonfunctioning pituitary adenomas. Acta Neurochir Suppl 91:51-54, 2004

42. Nomikos P, Ladar C, Fahlbusch R, Buchfelder M: Impact of primary surgery on pituitary function in patients with nonfunctioning pituitary adenomas - a study on 721 patients. Acta Neurochir (Wien) 146:27-35, 2004
43. O'Sullivan EP, Woods C, Glynn N, Behan LA, Crowley R, O'Kelly P, et al: The natural history of surgically treated but radiotherapy-naïve nonfunctioning pituitary adenomas. Clin Endocrinol (Oxf) 71:709-714, 2009

44. Oldfield EH: Editorial: management of invasion by pituitary adenomas. J Neurosurg 121:501-503, 2014

45. Park KJ, Kano H, Parry PV, Niranjan A, Flickinger JC, Lunsford LD, et al: Long-term outcomes after gamma knife stereotactic radiosurgery for nonfunctional pituitary adenomas. Neurosurgery 69:1188-1199, 2011

46. Park P, Chandler WF, Barkan AL, Orrego JJ, Cowan JA, Griffith KA, et al: The role of radiation therapy after surgical resection of nonfunctional pituitary macroadenomas. Neurosurgery 55:100-107, 2004

47. Petrovich Z, Yu C, Giannotta SL, Zee CS, Apuzzo ML: Gamma knife radiosurgery for pituitary adenoma: early results. Neurosurgery 53:51-61, 2003

48. Picozzi P, Losa M, Mortini P, Valle MA, Franzin A, Attuati $\mathrm{L}$, et al: Radiosurgery and the prevention of regrowth of incompletely removed nonfunctioning pituitary adenomas. J Neurosurg 102 Suppl:71-74, 2005

49. Pollock BE, Cochran J, Natt N, Brown PD, Erickson D, Link MJ, et al: Gamma knife radiosurgery for patients with nonfunctioning pituitary adenomas: results from a 15-year experience. Int J Radiat Oncol Biol Phys 70:1325-1329, 2008

50. Runge MJ, Maarouf M, Hunsche S, Kocher M, Ruge MI, El Majdoub F, et al: LINAC-radiosurgery for nonsecreting pituitary adenomas. Long-term results. Strahlenther Onkol 188:319-325, 2012

51. Sheehan JP, Kondziolka D, Flickinger J, Lunsford LD: Radiosurgery for residual or recurrent nonfunctioning pituitary adenoma. J Neurosurg 97 (5 Suppl):408-414, 2002

52. Sheehan JP, Niranjan A, Sheehan JM, Jane JA Jr, Laws ER, Kondziolka D, et al: Stereotactic radiosurgery for pituitary adenomas: an intermediate review of its safety, efficacy, and role in the neurosurgical treatment armamentarium. J Neurosurg 102:678-691, 2005

53. Sheehan JP, Starke RM, Mathieu D, Young B, Sneed PK, Chiang VL, et al: Gamma Knife radiosurgery for the management of nonfunctioning pituitary adenomas: a multicenter study. J Neurosurg 119:446-456, 2013

54. Snell JW, Sheehan J, Stroila M, Steiner L: Assessment of imaging studies used with radiosurgery: a volumetric algorithm and an estimation of its error. Technical note. J Neurosurg 104:157-162, 2006

55. Starke RM, Nguyen JH, Rainey J, Williams BJ, Sherman JH, Savage J, et al: Gamma Knife surgery of meningiomas located in the posterior fossa: factors predictive of outcome and remission. J Neurosurg 114:1399-1409, 2011

56. Starke RM, Williams BJ, Jane JA Jr, Sheehan JP: Gamma Knife surgery for patients with nonfunctioning pituitary macroadenomas: predictors of tumor control, neurological deficits, and hypopituitarism. J Neurosurg 117:129-135, 2012

57. Steiner LSJ, Lindquist C, Stroila M, Steiner M: Gamma surgery in cerebral vascular lesions, malformations, tumors, and functional disorders, in Schmidek HH, Roberts DW (ed): Schmidek \& Sweet Operative Neurosurgical Techniques: Indications, Methods, and Results, ed 5. Philadelphia: Saunders, 2006, Vol 1, pp 530-576

58. Turner HE, Stratton IM, Byrne JV, Adams CB, Wass JA: Audit of selected patients with nonfunctioning pituitary adenomas treated without irradiation-a follow-up study. Clin Endocrinol (Oxf) 51:281-284, 1999

59. van den Bergh AC, van den Berg G, Schoorl MA, Sluiter WJ, van der Vliet AM, Hoving EW, et al: Immediate postoperative radiotherapy in residual nonfunctioning pituitary adenoma: beneficial effect on local control without additional negative impact on pituitary function and life expectancy. Int J Radiat Oncol Biol Phys 67:863-869, 2007 
60. Vance ML: Pituitary adenoma: a clinician's perspective. Endocr Pract 14:757-763, 2008

61. Voges J, Kocher M, Runge M, Poggenborg J, Lehrke R, Lenartz D, et al: Linear accelerator radiosurgery for pituitary macroadenomas: a 7-year follow-up study. Cancer 107:13551364,2006

62. Williams BJ, Yen CP, Starke RM, Basina B, Nguyen J, Rainey J, et al: Gamma Knife surgery for parasellar meningiomas: long-term results including complications, predictive factors, and progression-free survival. J Neurosurg 114:1571-1577, 2011

63. Wilson PJ, De-Loyde KJ, Williams JR, Smee RI: A single centre's experience of stereotactic radiosurgery and radiotherapy for non-functioning pituitary adenomas with the Linear Accelerator (Linac). J Clin Neurosci 19:370-374, 2012

64. Woollons AC, Hunn MK, Rajapakse YR, Toomath R, Hamilton DA, Conaglen JV, et al: Non-functioning pituitary adenomas: indications for postoperative radiotherapy. Clin Endocrinol (Oxf) 53:713-717, 2000

65. Wowra B, Stummer W: Efficacy of gamma knife radiosurgery for nonfunctioning pituitary adenomas: a quantitative follow up with magnetic resonance imaging-based volumetric analysis. J Neurosurg 97 (5 Suppl):429-432, 2002

66. Zhang X, Fei Z, Zhang J, Fu L, Zhang Z, Liu W, et al: Management of nonfunctioning pituitary adenomas with suprasel- lar extensions by transsphenoidal microsurgery. Surg Neurol 52:380-385, 1999

\section{Disclosure}

The authors report no conflict of interest concerning the materials or methods used in this study or the findings specified in this paper.

\section{Author Contributions}

Conception and design: Sheehan, Pomeraniec, Dallapiazza, Jane. Acquisition of data: all authors. Analysis and interpretation of data: all authors. Drafting the article: Sheehan, Pomeraniec, Dallapiazza, Jane. Critically revising the article: Sheehan, Pomeraniec, Dallapiazza, Jane. Reviewed submitted version of manuscript: all authors. Approved the final version of the manuscript on behalf of all authors: Sheehan. Statistical analysis: Sheehan, Pomeraniec, Dallapiazza, Jane. Administrative/techni$\mathrm{cal} /$ material support: all authors. Study supervision: all authors.

\section{Correspondence}

Jason Sheehan, Department of Neurosurgery, Box 800212 ,

University of Virginia Health System, Charlottesville, VA 22908. email: jsheehan@virginia.edu. 